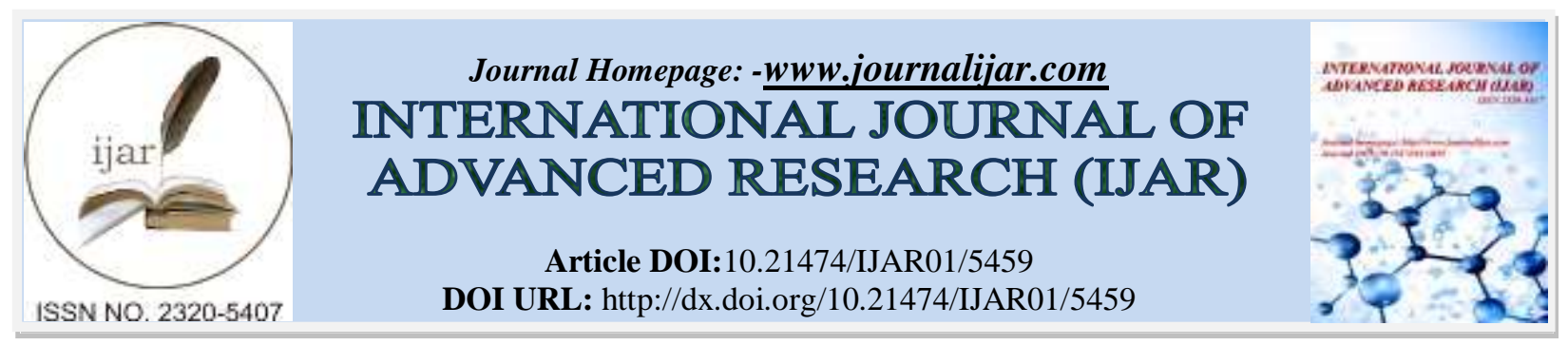

RESEARCH ARTICLE

\title{
ATTRIBUTES OF ORAL PATHOLOGISTS.
}

Dr. Bhuvan Nagpal.

M.D.S. (Oral Pathology \& Microbiology) (Gold Medalist). Consultant Oral Pathologist \& Chief Administrative Officer, Manglam Diagnostics, Hisar, Haryana, India - 125005.

\section{Manuscript Info}

Manuscript History

Received: 18 July 2017

Final Accepted: 20 August 2017

Published: September 2017

Key words:-

attributes, oral, pathology, pathologists,

dental, philosophical, knowingly

unknown, Shafer

\begin{abstract}
This paper is written for those medical and dental professionals who have special interest towards the domain of Oral Pathology. This paper is an amalgamation of scientific and philosophical perspective towards the community of Oral Pathologists. The author has tried to highlight and to make readers think about the "knowingly unknown" attributes of Oral Pathologists in an informal way. It is a blend of valuable experience of various pathologists across the world \& author's own comprehension about the field of Oral Pathology.
\end{abstract}

Copy Right, IJAR, 2017, All rights reserved.

\section{Introduction:-}

Keeping the following quotes of great scientist, Albert Einstein in mind:

"The value of college education is not the learning of many facts but the training of the mind to think"

"The true sign of intelligence is not knowledge but imagination."

There are some series of questions which author has in mind and want to ask the community of oral pathologists;

Who are we? What we do? Where we do? When we do? How we do? Why we do? and Do we Oral Pathology?

The options are Like, Love, Passionate about, All of the above, None of the above and Any better option (suggestion by the readers to the author)

Another quote as well as a graph which inspired author to ask some more questions to the readers of this article;

"You will never know what you have until you lose it, You always know what you have; you just never think you would lose it." 


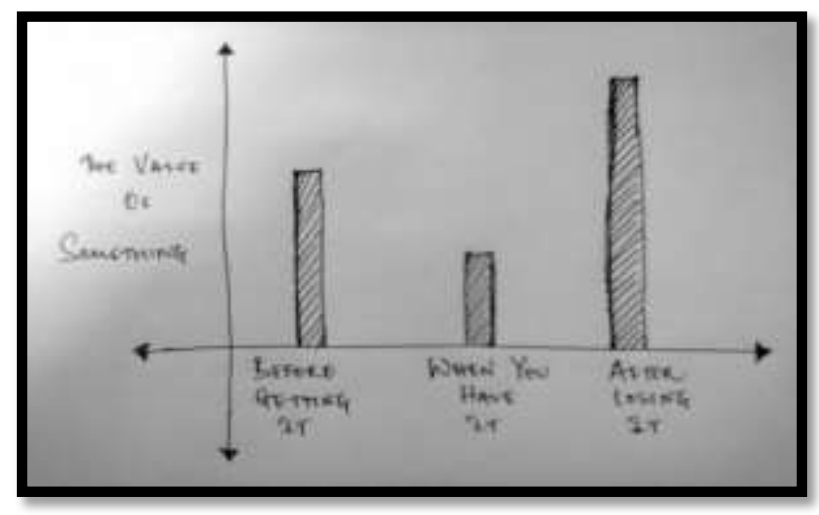

Graph 1:- depicts the value of something when u have it and after losing it.

1. Had pathology not been there; what would have been the story of medicine?

2. Do we really value the plethora of information about pathology in general?

3. Imagine if all the information regarding pathology is lost; what will be the situation of medical science?

Now, the question arises; what is pathology? Pathology is all about diseases as it is derived from two words 'patho' which means disease \& 'logy' which means study of. Therefore, it is study of disease.

Starting with the definition of Oral Pathology; it is defined as the speciality of dentistry and pathology which deals with the nature, identification and management of diseases affecting the oral and maxillofacial region. It is a science that investigates the causes, processes and effects of these diseases. According to Dr. William G. Shafer, Oral Pathology represents the confluence of the basic sciences and clinical dentistry. The Dental Council of India (DCI) has given the following objectives for the subject of Oral Pathology under the MDS curriculum: ${ }^{1}$

1. To train a post graduate dental surgeon so as to ensure higher competence in both general and special pathology dealing with the nature of oral diseases, their causes, processes and effects.

2. An oral pathologist is expected to perform routine histopathological evaluation of specimens relating to oral and perioral tissues, to carry out routine diagnostic procedures including hematological, cytological, microbiological, Immunological and ultra structural investigations.

3. He/she is expected to have an understanding of current research methodology, collection and interpretation of data, ability to carry out research projects on clinical and or epidemiological aspects, a working knowledge on current databases, automated data retrieval systems, referencing and skill in writing scientific papers.

4. He/she is expected to present scientific data pertaining to the field, in conferences both as poster and verbal presentations and to take part in group discussions.

Who is a pathologist?

According To Dyke ${ }^{2}$, A pathologist is "A physician using somewhat different methods of observation a microscope rather than the stethoscope, the results of chemical \& bacteriological investigations rather than the unaided senses." McLendon has aptly described pathologist as Physician, concerned with human suffering and willing to make considerable efforts to decrease this suffering; Scientist with an enquiring mind, using advanced tools available to study disease; Educator sharing his knowledge, methods of scientific inquiry and spirit with his students and other medical colleagues and Leader of both pathology and medicine, because he believes in quality assurance and the role of pathology in the general advancement of medicine. ${ }^{3}$

The other names for pathologists according to the author can be; Microscopic or Tissue Physicians because pathologists are the ones who observe the cells and tissues at microscopic level and come to conclusion for a diagnosis. They are also called Laboratory Physicians because they work in laboratory in order to make conclusive diagnosis for a particular disease by carrying out different investigations. Pathologists can also be called as Disease detectives because like detective who solves a mysterious case with his own thinking and reasoning after observing the crime site, case victims and criminals; in the same way a pathologist also detects disease by his own observation and thinking. In the opinion of author, 
Oral Pathologists work like movie directors, because they are the professionals who direct the treatment of the patient by making diagnosis for the patient's disease. A pathologist observes the slides of tissues obtained from biopsy specimens under microscope and detects disease. So the author has made an apt quote for the same; "Every slide is a mystery, A pathologist solves it by history" (which the patient gives)

To solve the mystery of disease/slide, an oral pathologist makes use of the following abilities:-

1. Observation skills through the proper usage of eyes

2. Visual memory and thinking skills through the proper use of brain

3. Knowledge obtained through books, journals and experience

4. Microscope

5. Biopsy specimen from the patient

6. Laboratory

7. Written report through the proper use of words

Observation skills through the proper usage of eyes:-

The author has made a quote by observing and comparing the beautiful eyes of a model or movie star with the old and sunken eyes of Oral Pathologist; "The beauty of the eyes is not how they look like, but how they see." We all know that eyes are the mirror of soul. In authors opinion; "Eyes are the mirror by which the information in slide is reflected to an oral pathologist." Eyes are the sensory organs of vision. For a pathologist, they are sensory organs of observation.

Bill Bass from USA says "You have to be a good observer. You have to be an observer of minutiae - to look at the little things. Little things make a difference. And you have to know what those little things mean - so that's where your academic training comes in."Elaine Jaffe from USA says "I think that you have to be born with a certain visual aptitude. I can tell in the first month when I sit down with a resident whether they have got it or not. Unfortunately I feel there are some people who may choose pathology not really knowing what it is, or not having tried it, that are not well suited to it. Actually a colleague of mine told me that one question she always asks residency applicants is about their hobbies, and if they like art or photography in particular she feels they are more likely to be good pathologists than if they have other orientations." Juan Rosai says "There is no question that some people have a better 'eye' than others. There are pathologists who have been in the field for 40 years or more and who have tremendous experience but will never go beyond a certain point, so that a third year resident with a good 'eye' will see something that they have not." ${ }^{4}$ ' Because of the constant use of eyes for slides observation by oral pathologists, visual strain is the most common occupational hazard related to oral pathologists followed by back pain, fibromyalgia, neck pain, upper extremity discomfort, pain in hand \& fingers (mostly right side).

\section{Visual memory and thinking skills through the proper use of brain:-}

As Netaji Subhash Chandra Bose has rightly said during Indian Freedom Movement "You give me Blood, I will give you Freedom." Keeping the above quote in mind, the author has made a similar quote; "You give me Brain, I will give you Diagnosis."

Brain is the higher centre or central intelligence agency of a living being. For a pathologist, it helps him in the thinking process, processing of the information gained through books and journals, connecting all the clues while observing slides and patient's history in order to come to final conclusion, reasoning \& judgement and finally storing the information in the form of visual memory.Academicians in medical and dental schools regularly say this quote during anatomy dissection hall; "Eyes see what the brain knows." This quote holds true for pathology also. Our eyes can only recognize only those structures whether cells or tissues in slides under microscope which our brain knows. The memory of an oral pathologist is majorly visual. He remembers slides with a visual memory. Pathologists are united in the view that having a strong visual memory. Above all, a talent for pattern recognition is a crucial attribute of a good pathologist.

In fact, as Juan Rosai comments, "if we knew exactly how to test this quality, that would be very useful, because then we could tell people, 'You are not really fit for this business'."'You have to be able to build pictures in your mind. That's why the training takes a long time," says Ken Hillan, since pathologists must develop this innate visual ability and marry it to rigorous scientific learning. "There's no doubt pathology is very much based in science." In addition, many interviewees cite the need for observational skills, attention to detail, patience and a methodical approach to work. Juan Rosai further stated that for identifying new disease entities, stresses that alongside these 
physical attributes pathologists also need to have 'imagination' and 'conviction' and should not be afraid to question. "That's one of the things I have been telling people over the years: 'If you see something that's doesn't fit any disease you know or that is in the books, don't assume automatically that you don't recognize it because you are no good. Maybe it is something that has not yet been described'." James Ironside makes a similar point: being a good pathologist is "about having an open mind and looking beyond the clinical expectation". He tells the story of discovering the new variant of Crutzfeld Jacob Disease, and how important both good pattern recognition and being open to new interpretations were on this occasion ${ }^{4}$.

\section{Knowledge obtained through books, journals and experience:-}

Knowledge is gained when information is combined with experience. Another quote by Albert Einstein which can be aptly applied to the profession of Oral Pathologists; "I have not eaten enough of the tree of knowledge though in my profession I am obligated to feed on it regularly". Immanuel Kant's nice quote on experience; "There can be no doubt that all our knowledge begins with experience. But from where this information and experience comes from? Information comes from reading different textbooks \& scientific journals on different topics of oral pathology and oncology and experience comes from practicing the profession over a period of time which inturn means reviewing numerous slides daily. With experience the accuracy of diagnostic skills increases multifold. Few quotations about experience;

"Experience is not what happens to you; it's what you do with what happens to you." "Most good judgement comes from experience; most experience comes from bad judgement."

\section{Microscope:-}

Microscope is that instrument by which an oral pathologist comes to diagnosis by seeing through the tissues placed on the glass slide under the coverslip. According to author, it is the 'Stethoscope' of oral pathologist. In nutshell; a pathologist listens to the heart beat of tissues through the usage of microscope.

\section{Biopsy specimen from the patient:-}

For oral pathologist, biopsy specimen is equivalent to patient. The tissue obtained after biopsy procedure goes through series of tissue processing and finally a tissue slide is made which is stained with routine hematoxylin and eosin staining. The vitals which Oral Pathologists look for are Cell morphology (cytoplasm \& nucleus), Basement membrane and Inflammation. Signs and symptoms in Oral Pathology by which microscopic physicians (oral pathologists) make a diagnosis are Necrosis, Apoptosis, Different histopathologic bodies, cells \& patterns, Inflammatory cells and Dysplasia.

Using the below mentioned bollywood movie songs as metaphor,

"Sanson ki jarurat hai jaise.............sanson ki jarurat hai jaise.......

Zindagi ke liye......bas ek sanam chahiye.........aashiqui ke liye..........."

"Dil cheez kya hai..........aap meri jaan leejiye.........

Bus ek baar mera kaha ............maan leejiye......"

The author has made an 'oral pathologist song' which he should recite to the patients;

"Diagnosis ki jarurat hai jaise......diagnosis ki jarurat hai jaise........"

"Treatment ke liye ......... bas ek biopsy chahiye ............histopathology report ke liye "Histopathology report cheez kya hai..........aap IHC (Immunohistochemistry) report lee jiye........."

"Bus ek baar biospy............karva lee jiye............"

\section{Laboratory:-}

Laboratory is a place where different diagnostic procedures like hematology, serology, cytopathology, histopathology and microbiology are carried out and according to author; it is Oral Pathologist's Temple.

Analogous to clinical examination in medicine, surgical procedures in surgery, tooth preparation \& root canal treatment in endodontics and bracket placement \& force application in orthodontics; oral pathologists do histopathological examination. The broad and basic pathologic processes are Inflammation, Neoplasia, Developmental, Hemodynamic and Immune - mediated.

Ken Hillan from UK says "The histopathology diagnostic microscopy is definitely an art form, and it's being able to put together pictures in your mind; even when you may just see one corner of a picture in your biopsy, you have to 
be able to put that into the whole picture of what's going on in the organ. Being able to do that visually is one of the key things about histopathology. But there's no doubt that it's very much based in science. By appreciating the patterns and the things that are changing in the tissues, and then bringing in additional scientific information, such as gene expression in the tissues, you can build both the artistic and the scientific picture that helps you to understand disease." Paola Domizio from UK asks "What makes a good pathologist? First of all, I think you have to be good at pattern recognition. You have to be thorough in your thinking, "Well, if I haven't seen this before, what must I do to try and make the diagnosis? Must I do some more special stains? Must I show it to somebody else? Must I read up in the books about it?" And you have to be quite determined to find out. Rosai explores the challenge of understanding what goes on when a pathologist makes a diagnosis, "because it works to some extent at a subconscious level". He and Francisco Gonzáles-Crussí both tell the amusing story of an intriguing and ultimately unsuccessful experiment, involving "some technological gizmo", to deconstruct the process of diagnosis. ${ }^{4}$

\section{Written report through the proper use of words:-}

Carol L. Rickard says "words can be powerful, put into action, they become life changing." Paola Domizio says "You have to be good at written communication, believe it or not, because your way of communicating what you think about a particular case is through the written word. When you read a report you should be able to picture what the pathologist who's written that report is seeing, and agree with their interpretation. And actually not all histopathologists are very good at that."Domizio goes on to point out that since the main means of communication is through written reports, "You have to have a skill in putting what you're seeing down the microscope into words." A very difficult thing in surgical pathology is to express in words the mental process you use in order to reach a diagnosis, because it works to some extent at a subconscious level. People will show you a case, you realise immediately that it is an alveolar rhabdomyosarcoma, so you make that diagnosis. But if they ask you, "Why did you say that?" then you have to think! You go ahead and list the reasons or criteria, but you haven't thought of them, at least consciously, while you were looking. It was just an instantaneous recognition. ${ }^{4}$

What is histopathology report? The author says "It is nothing but a blend of good slide observation along with thorough thinking with proper reasoning \& judgement which is put together into the beauty of words" Dr. Vineet Gupta has described histopathology report in a wonderful manner; Section shows beauty of pathology decorated with blue \& pink colors mimicking colors of life \& rejuvenating my eyes. The epithelium - connective tissue junction seems to be like horizon, where I stand alone asking god- "Sir, why should you have created pathology for every aspect of histology??" He answered me back- "My son, if pathology wouldn't have been there, what is the importance of normal, man never would have taken care."

Now after reading the article, the author asks the same question which was asked in the beginning of the article. Do we ___ Oral Pathology? The options are Like, Love, Passionate about, All of the above, None of the above and Any better option can also be suggested. Here, the author gives clue to the readers by giving the dictionary meanings of the words; like means to find something pleasant / attractive, to feel about, inclination or preference, love means a strong feeling of affection and passion means intense desire or enthusiasm for something, anything which arouses great enthusiasm, compelled by intense emotions.

\section{Conclusion:-}

To summarize, an oral pathologist uses eyes to observe the slides using microscope, interpret it through brain and finally comes to diagnosis through knowledge and skill of reasoning gained with experience which is presented in the form of histopathology report. The author concludes the article by the wonderful quote of Gabrielle Bernstein; "Allow your passion to become your purpose and it will one day become you profession."

\section{Acknowledgement and dedication:-}

The author has dedicated this paper to the community of Oral Pathologists because the future of dentistry lies on the shoulders of oral pathologists and Professor Dr. William G. Shafer; a great Oral Pathologist who was a source of inspiration for him through means of his textbook. 


\section{References:-}

1. Dental Council of India (DCI) Revised M.D.S. Course Regulations, Gazette of India2007:89.

2. Dyke SC. As quoted by Forster WD. Pathology as a profession in Great Britain and the early history of The Royal College of Pathologists. The Royal College of Pathologists: College Handbook; 1984.

3. McLendon WW. A historical perspective as a compass for the future of pathology. Arch Pathol Lab Med 1986;110:284-8,778-9.

4. Sue Armstrong. A matter of life and death: Inside the hidden world of pathologist. Dundee University Press;2008. 